\title{
Liste des habilitations à la direction de recherches soutenues à la section pendant l'année 2011-2012
} par ordre alphabétique des noms d'auteur

\section{OpenEdition}

\section{Journals}

Édition électronique

URL : https://journals.openedition.org/ashp/1413

DOI : 10.4000/ashp.1413

ISSN : 1969-6310

Éditeur

Publications de l'École Pratique des Hautes Études

Édition imprimée

Date de publication : 1 septembre 2013

Pagination : $x \mathrm{vi}$

ISSN : 0766-0677

Référence électronique

"Liste des habilitations à la direction de recherches soutenues à la section pendant l'année 2011-2012 », Annuaire de l'École pratique des hautes études (EPHE), Section des sciences historiques et philologiques [En ligne], 144 | 2013, mis en ligne le 16 octobre 2014, consulté le 05 novembre 2021. URL : http://journals.openedition.org/ashp/1413 ; DOI : https://doi.org/10.4000/ashp.1413

Ce document a été généré automatiquement le 5 novembre 2021.

Tous droits réservés : EPHE 


\section{Liste des habilitations à la direction de recherches soutenues à la section pendant l'année 2011-2012}

par ordre alphabétique des noms d'auteur

1 Mongols bouddhistes aux frontières de la Chine (XIII ${ }^{e}-\mathrm{XXI} I^{e}$ siècles). Pèlerinages et culture matérielle, par $\mathrm{M}^{\mathrm{me}}$ Isabelle CHARLEUX, sous la direction de M. Charles RAMBLE, le 26 juin 2012.

2 Institutions et sociétés des cités grecques aux époques classique et hellénistique, par M. Pierre FRÖHLICH, sous la direction de M. Jean-Louis FERRARY, le 19 novembre 2011.

3 La danse des Charites. Monnaies, échanges et sociabilités au début de l'Empire romain, par M. Arnaud SUSPENE, sous la direction de M. Jean-Louis FERRARY, le 21 novembre 2011.

4 Élites politiques et culturelles en Iran et en Asie centrale : études historiographiques et patrimoine manuscrit inédit ( $\mathrm{XV}^{e}$-XIXe siècle), par $\mathrm{M}^{\mathrm{me}}$ Maria SzUPPE, sous la direction de M. François DérocHE, le 10 décembre 2011.

INDEX

Thèmes : Vie de la Section des sciences historiques et philologiques 